\title{
Pharmacogenetics of telatinib, a VEGFR-2 and VEGFR-3 tyrosine kinase inhibitor, used in patients with solid tumors
}

\author{
Neeltje Steeghs • Hans Gelderblom • Judith Wessels • \\ Ferry A. L. M. Eskens • Natasja de Bont • \\ Johan W. R. Nortier • Henk-Jan Guchelaar
}

Received: 15 September 2009 / Accepted: 26 October 2009 / Published online: 19 November 2009

(C) The Author(s) 2009. This article is published with open access at Springerlink.com

\begin{abstract}
Summary Purpose Telatinib is an orally active smallmolecule tyrosine kinase inhibitor of kinase insert domain receptor (KDR; VEGFR-2) and fms-related tyrosine kinase 4 (FLT4; VEGFR-3). This study aims at the identification of relationships between single nucleotide polymorphisms (SNPs) in genes encoding for transporter proteins and pharmacokinetic parameters in order to clarify the significant interpatient variability in drug exposure. In addition, the potential relationship between target receptor polymorphisms and toxicity of telatinib is explored. Methods Blood samples from 33 patients enrolled in a phase I dose-escalation study
\end{abstract}

The submission is original work not previously published in any substantial part, is not under consideration of publication elsewhere. There are no actual or potential conflicts of interest capable of influencing judgment on the part of any author. The manuscript has been read and approved for submission by all authors.

N. Steeghs $\cdot$ H. Gelderblom $(\bowtie) \cdot$ J. W. R. Nortier

Department of Clinical Oncology,

Leiden University Medical Centre,

K1-P, P.O Box 9600, 2300 RC Leiden,

The Netherlands

e-mail: A.J.Gelderblom@lumc.nl

J. Wessels • H.-J. Guchelaar

Department of Clinical Pharmacy and Toxicology,

Leiden University Medical Center,

Leiden, The Netherlands

F. A. L. M. Eskens

Department of Medical Oncology,

Erasmus University Medical Center,

Rotterdam, The Netherlands

N. de Bont

Bayer Pharmaceuticals Corporation,

Mijdrecht, The Netherlands of telatinib were analyzed. For correlation with dose normalized $\mathrm{AUC}_{(0-12)}$, ATP-binding cassette $(\mathrm{ABC}) \mathrm{B} 1$ (ABCB1), $A B C C 1$, and $A B C G 2$ were the genes selected. For correlation with telatinib toxicity, selected genes were the drug target genes KDR and FLT4. Results No association between dose normalized $\mathrm{AUC}_{(0-12)}$ and drug transporter protein polymorphisms was observed. In addition, no association between toxicity and KDR or FLT4 genotype or haplotype was seen. Conclusions Our pharmacogenetic analysis could not reveal a correlation between relevant gene polymorphisms and clinical and pharmacokinetic observations of telatinib.

Keywords Pharmacogenetics · VEGFR - Telatinib . Cancer $\cdot$ Angiogenesis

\section{Introduction}

Single nucleotide polymorphisms (SNPs) in genes encoding for drug transporters and drug targets contribute to interindividual heterogeneity of drug efficacy and toxicity in cancer therapy $[1,2]$. This type of research is referred to as pharmacogenetics. In our current study we analyze pharmacogenetic factors likely to be involved in telatinib disposition and mechanism of action.

Telatinib (BAY 57-9352) is an orally active, smallmolecule tyrosine kinase inhibitor of kinase insert domain receptor $(K D R$; vascular endothelial growth factor receptor (VEGFR)-2) and fms-related tyrosine kinase 4 (FLT4; $V E G F R-3)$. Telatinib is metabolized by various cytochrome P450 (CYP) isoforms including CYP3A4/3A5, CYP2C8, $C Y P 2 C 9$, and $C Y P 2 C 19$ as well as by uridine diphosphate glucuronosyltransferase 1A4 (UGT1A4), with the formation of the $\mathrm{N}$-glucuronides of telatinib as the major biotransfor- 
mation pathway in man. In vitro studies showed telatinib to be a weak substrate of the adenosine triphosphate binding cassette $(\mathrm{ABC}) \mathrm{B} 1(A B C B 1)$ transporter (data on file at Bayer Pharmaceuticals Corporation) [3].

In a phase I and pharmacological study we showed that pharmacokinetics (PK) of telatinib were dose proportional [4]. However, substantial interpatient variability was observed $\left(\mathrm{C}_{\max }\right.$ and $\mathrm{AUC}_{(0-12)} \%$ coefficient of variation $\left.20-150 \%\right)$ and no clear association between telatinib exposure and toxicity could be established. However, in this class of agents an increase in toxicity is generally observed with increasing dose $[5,6]$. Although in general limited information on drug metabolism and toxicity is available in early stages of drug development, pharmacogenetic research may be valuable. For example, if significant side effects could be linked to a certain drug transporter polymorphism, this could influence further drug development or could become an important issue in patient selection.

The current study examines the potential relationships between SNPs in genes coding for transporter proteins and pharmacokinetic parameters of telatinib in order to identify factors contributing to the significant interpatient variability in drug exposure. In addition, this study explores the potential relationship between target receptor polymorphisms and toxicity of telatinib.

\section{Methods}

This study was conducted in a subset of patients enrolled into a two-centre, phase I dose-escalating study of telatinib [4]. The aim of this exploratory pharmacogenetic study was to identify possible relationships between SNPs in genes coding for drug transporters and PK parameters; and drug target related SNPs and side effects of telatinib. From 33 of the 53 patients treated in the phase I study residual blood samples were available for pharmacogenetic analyses. Demographic, toxicity and pharmacokinetic characteristics were comparable for included and excluded patients (data not shown). Four of these 33 patients were treated with telatinib oral solution or $25 \mathrm{mg}$ tablets, the remaining patients with $150 \mathrm{mg}$ tablets.

Since bioavailability of the telatinib formulations differ, a decision was made to restrict the current analysis to one telatinib formulation. Therefore, in the association analysis with PK, only the 29 patients treated with the $150 \mathrm{mg}$ tablets were included.

Patients and samples

Eligibility criteria, drug administration procedures and clinical and pharmacokinetic results are described in detail elsewhere [4]. Briefly, patients with histologically or cytologically confirmed advanced or metastatic solid tumors for whom no standard therapy was available, with an Eastern Cooperative Oncology Group (ECOG) performance status $\leq 2$ were eligible. Telatinib was administered orally, once daily (od) or twice daily (bid), on a continuous basis. The clinical trial had a standard $3+3$ phase I dose escalation study design. Because of significant interpatient variability in pharmacokinetics the decision was made to expand all cohorts to a minimum of six patients from the second cohort onwards. Response evaluation was performed every 2 cycles and was assessed according to RECIST [7].

Residual blood samples taken for the routine patient care were stored at $-20^{\circ} \mathrm{C}$ at the local hospital laboratories. One frozen blood sample for each patient was collected from the two participating hospitals (Leiden University Medical Center, Leiden and Erasmus Medical Center, Rotterdam). All samples were anonymized by a third party, according to the instructions given in the "Code of Conduct for the use of data in Health Research" and "Code for Proper Secondary Use of Human Tissue" (www.federa.org). Approval from the institutional medical ethical review boards was obtained.

\section{Pharmacokinetic and toxicity parameters}

PK evaluation was performed by collecting blood samples on days 1 and 14 of cycle 1 , and day 14 of cycles 2 and 4 . Pharmacokinetic parameters were calculated by noncompartmental analysis using WinNonlin (version 4.1.a).

In this study cycle 1 day 14 (representing steady-state) dose normalized $\mathrm{AUC}_{(0-12)}$, calculated as $\mathrm{AUC}_{(0-12)} /$ actual dose administered, was selected as the most important PK parameter to associate with transporter genetic polymorphisms. Dose normalized $\mathrm{C}_{\max }, \mathrm{T}_{\max }$ and $\mathrm{T}_{1 / 2}$ were also selected for association analyses.

Patients were evaluated for adverse events and toxicity according to the National Cancer Institute Common Toxicity Criteria (NCI-CTC), version 3.0. In general, the NCI-CTC toxicity score distinguishes between mild (grade 1), moderate (grade 2), severe (grade 3), lifethreatening or disabling toxicity (grade 4) and death related to adverse events (grade 5). Telatinib administration resulted in limited toxicity. Grade 3-4 toxicity was only seen in 3 patients. Therefore, despite the fact that grade 3-4 toxicity is more clinically relevant, the occurrence of any grade 1-4 toxicity was considered to be the best candidate parameter for association analyses with drug target receptor genetic polymorphisms. Since toxicity observed in the first cycle was limited we decided to use overall toxicity observed in all treatment cycles for statistical association studies. In addition, hypertension is considered to be one of the more serious telatinib side 
effects, and grade 1-4 hypertension was also selected for association analyses.

\section{Selection of candidate genes}

Candidate genes were selected based on the information of preclinical pharmacology studies as reported in the Investigator's brochure (Bayer Pharmaceutical Corporation, data on file). For association with PK parameters $A B C B 1, A B C C 1$, and $A B C G 2$ were the genes selected. For correlation with telatinib toxicity selected genes were the drug target genes encoding KDR and FLT4. For the major biotransformation pathway in man, the formation of the $\mathrm{N}$-glucuronides through UGT1A4, no SNP met the criteria for selection described below.

The SNPs were selected, taking into consideration one or more of the following criteria: validated SNP assay, SNP causes preferably non-synonymous amino acid change, indications for clinical relevance from previous publications, and a preferred minor genotype frequency of $\sim 10 \%$.

DNA extraction and SNP analysis methods

DNA was isolated from whole blood samples with MagNA Pure DNA Isolation kit (Roche Diagnostics, Almere, The Netherlands). DNA concentrations were quantified using a NanoDrop spectrophotometer (Isogen, IJsselstein, The Netherlands). Taqman assays were obtained from Applied Biosystems (Applied Biosystems, Nieuwerkerk aan den IJssel, The Netherlands). As a quality control, 4 samples were genotyped in duplicate for all assays and 2 assays were tested in duplicate on all samples. As negative controls water was used. Overall, no inconsistencies were observed in the results.

The following SNPs were analyzed: $A B C B 13435 \mathrm{C}>\mathrm{T}$ (rs1045642), $A B C B 1$ 1236C $>\mathrm{T}$ (rs1128503), $A B C B 1$ $2677 \mathrm{G}>\mathrm{A} / \mathrm{T}$ (rs2032582), $A B C B 1-129 \mathrm{~T}>\mathrm{C}, A B C C 1 \mathrm{C}>\mathrm{G}$ (rs129081), $A B C C 1$ 825T $>\mathrm{C}$ (rs246221), $A B C C 1$ 1062T $>\mathrm{C}$ (rs35587), $A B C C 1$ 2012G $>\mathrm{T}$ (rs45511401), $A B C G 2$ $346 \mathrm{G}>\mathrm{A}(\mathrm{rs} 2231137), A B C G 2 \quad 421 \mathrm{C}>\mathrm{A}(\mathrm{rs} 2231142)$, FLT4 1480A $>\mathrm{G}(\mathrm{rs} 307826)$, FLT4 2670C $>\mathrm{G}(\mathrm{rs} 448012)$, $K D R$ 1719A $>\mathrm{T}$ ( $\mathrm{rs} 1870377), K D R \quad-604 \mathrm{~T}>\mathrm{C}(\mathrm{rs} 2071559)$, and $K D R 1192 \mathrm{G}>\mathrm{A}$ (rs2305948).

SNP genotyping was performed with BIOMARK 48.48 dynamic array (Fluidigm Corporation, South San Francisco, CA, USA). All assays were performed according to protocols provided by the manufacturer.

Statistical analysis

Differences in pharmacokinetic and toxicity parameters among genotypes were analyzed by Student's $t$-test, ANOVA or Kruskal-Wallis test for continuous variables or chi-square test for dichotomous variables where appropriate. For toxicity, differences in genotype distribution were tested by $3 \times 2$ cross-tabulations for each genotype, and by $2 \times 2$ crosstabulations for carriers versus noncarriers, with analysis by 2-sided chi-square test.

Polymorphisms within a gene were tested with the chisquare test $(P$-value $<0.05)$ to detect linkage disequilibrium (LD). If LD between SNPs was detected, haplotypes were determined for each individual with gPLINK (http://pngu. mgh.harvard.edu/purcell/plink/) [8]. No phase uncertainty in the defined haploblocks and haplotypes $\left(\mathrm{Rh}^{\wedge} 2>0.98\right)$ was seen.

Associations between the number of copies of a haplotype and clinical parameters were performed using a chi-square test for dichotomous variables and Student's $t$-test, ANOVA or Kruskal-Wallis test for continuous variables.

Table 1 Patient characteristics, overall telatinib-induced toxicity, pharmacokinetic results and outcome data of telatinib treated patients

\begin{tabular}{|c|c|}
\hline Characteristics & Patients (n (\%)) \\
\hline \multicolumn{2}{|l|}{ Gender } \\
\hline Male & $15(45)$ \\
\hline Female & $18(55)$ \\
\hline \multicolumn{2}{|l|}{ Age, years } \\
\hline Mean (range) & $53(22-77)$ \\
\hline \multicolumn{2}{|l|}{ Tumor type } \\
\hline Soft tissue sarcoma & $9(27)$ \\
\hline Colorectal cancer & $5(15)$ \\
\hline Adrenal cancer & $3(9)$ \\
\hline Ovarian cancer & $3(9)$ \\
\hline Cholangiocarcinoma & $2(6)$ \\
\hline Esophageal cancer & $2(6)$ \\
\hline Melanoma & $2(6)$ \\
\hline Miscellaneous & $7(21)$ \\
\hline \multicolumn{2}{|l|}{ ECOG performance score } \\
\hline 0 & $9(27)$ \\
\hline 1 & $24(73)$ \\
\hline \multicolumn{2}{|l|}{$\mathrm{Nr}$ of previous treatment lines } \\
\hline Mean (range) & $3(0-13)$ \\
\hline \multicolumn{2}{|l|}{ Toxicity } \\
\hline Any toxicity grade $1-4$ & $23(70)$ \\
\hline Any toxicity grade 3 or 4 & $3(9)$ \\
\hline Hypertension grade $1-4$ & $7(21)$ \\
\hline Hypertension grade 3 or 4 & $2(6)$ \\
\hline \multicolumn{2}{|l|}{ Pharmacokinetic parameters } \\
\hline \multicolumn{2}{|l|}{ Mean (range) } \\
\hline $\begin{array}{l}\text { Dose normalized } \mathrm{AUC}_{(0-12)}(\mu \mathrm{g} \cdot \mathrm{hr} / \mathrm{L} \text { per } \mathrm{mg} \\
\text { of dose) }\end{array}$ & $9.26(0.98-34.60)$ \\
\hline \multicolumn{2}{|l|}{ Number of treatment courses } \\
\hline Mean (range) & $5.5(1-30)$ \\
\hline
\end{tabular}

ECOG Eastern Cooperative Oncology Group, Dose normalized AUC: area under the curve/dose 
All statistical analyses were performed using SPSS 16.0 software (SPSS, Chicago, IL) and were two-sided, with a level of significance of $\alpha=0.05$.

\section{Results}

Baseline patient characteristics, observed treatment-related toxicities, pharmacokinetics and treatment duration are presented in Table 1. Telatinib doses used were $20 \mathrm{mg}$ od $(n=2), 75 \mathrm{mg}$ od $(n=2), 150 \mathrm{mg}$ bid $(n=4), 300 \mathrm{mg}$ bid $(n=4), 600 \mathrm{mg}$ bid $(n=3), 900 \mathrm{mg}$ bid $(n=16)$, and $1,500 \mathrm{mg}$ bid $(n=2)$. Our population comprised $100 \%$ Caucasians with $45 \%$ males and 55\% females. Most frequent tumor types were soft tissue sarcomas (27\%) next to colorectal cancer $(15 \%)$ together with a high number of other tumor types (58\%) consistent with the phase I nature of the clinical study. Median number of treatment courses was 5.5, ranging from 1 to 30 , with one course being 3 weeks of telatinib administration.
Table 2 Association between genetic polymorphisms and telatinib pharmacokinetic data. Dose normalized AUC

\begin{tabular}{|c|c|c|c|c|c|c|}
\hline \multirow[b]{2}{*}{ Gene } & \multirow[b]{2}{*}{ Polymorphism } & \multirow[b]{2}{*}{ Genotype } & \multirow[b]{2}{*}{ No. } & \multicolumn{3}{|c|}{ Dose normalized AUC } \\
\hline & & & & Mean & & SD \\
\hline \multirow[t]{16}{*}{$A B C B 1$} & $3435 \mathrm{C}>\mathrm{T}$ & $\mathrm{CC}$ & 7 & 7.30 & & 3.35 \\
\hline & & $\mathrm{CT}$ & 16 & 11.10 & & 9.10 \\
\hline & & $\mathrm{TT}$ & 6 & 6.65 & & 4.76 \\
\hline & & $P$-value & & & 0.343 & \\
\hline & $1236 \mathrm{C}>\mathrm{T}$ & $\mathrm{CC}$ & 9 & 7.84 & & 3.26 \\
\hline & & CT & 15 & 11.60 & & 9.44 \\
\hline & & $\mathrm{TT}$ & 5 & 4.82 & & 1.81 \\
\hline & & $P$-value & & & 0.180 & \\
\hline & $2677 \mathrm{G}>\mathrm{A} / \mathrm{T}$ & GG & 9 & 7.84 & & 3.26 \\
\hline & & TG & 15 & 11.60 & & 9.44 \\
\hline & & $\mathrm{TT}$ & 5 & 4.82 & & 1.81 \\
\hline & & $P$-value & & & 0.180 & \\
\hline & $-129 \mathrm{~T}>\mathrm{C}$ & TT & 26 & 8.67 & & 7.51 \\
\hline & & $\mathrm{TC}$ & 2 & 15.65 & & 6.06 \\
\hline & & $\mathrm{CC}$ & 1 & 11.79 & & n.a. \\
\hline & & $P$-value & & & 0.134 & \\
\hline \multirow[t]{15}{*}{$A B C C 1$} & $\#(\mathrm{rs} 129081)$ & $\mathrm{CC}$ & 5 & 10.22 & & 7.57 \\
\hline & & $\mathrm{GC}$ & 15 & 10.44 & & 9.07 \\
\hline & & GG & 9 & 6.77 & & 3.16 \\
\hline & & $P$-value & & & 0.494 & \\
\hline & $825 \mathrm{~T}>\mathrm{C}$ & $\mathrm{TT}$ & 18 & 8.26 & & 6.54 \\
\hline & & $\mathrm{TC}$ & 11 & 10.90 & & 8.76 \\
\hline & & $P$-value & & & 0.362 & \\
\hline & $1062 \mathrm{~T}>\mathrm{C}$ & $\mathrm{TT}$ & 17 & 8.36 & & 6.73 \\
\hline & & $\mathrm{TC}$ & 10 & 9.95 & & 9.15 \\
\hline & & $\mathrm{CC}$ & 2 & 13.45 & & 3.30 \\
\hline & & $P$-value & & & 0.631 & \\
\hline & $2012 \mathrm{G}>\mathrm{T}$ & GG & 24 & 8.80 & & 5.89 \\
\hline & & GT & 4 & 13.46 & & 14.57 \\
\hline & & $\mathrm{TT}$ & 1 & 3.63 & & n.a. \\
\hline & & $P$-value & & & 0.552 & \\
\hline \multirow[t]{6}{*}{$A B C G 2$} & $346 \mathrm{G}>\mathrm{A}$ & GG & 25 & 9.78 & & 7.83 \\
\hline & & $\mathrm{AG}$ & 4 & 6.00 & & 2.69 \\
\hline & & $P$-value & & & 0.353 & \\
\hline & $421 \mathrm{C}>\mathrm{A}$ & $\mathrm{CC}$ & 23 & 8.95 & & 7.96 \\
\hline & & $\mathrm{CA}$ & 6 & 10.48 & & 5.26 \\
\hline & & $P$-value & & & 0.661 & \\
\hline
\end{tabular}


Table 3 Association between genetic polymorphisms and telatinib pharmacokinetic data. Dose normalized $\mathrm{C}_{\max }, \mathrm{T}_{1 / 2}$ and $\mathrm{T}_{\max }$

\begin{tabular}{|c|c|c|c|c|}
\hline \multirow[b]{2}{*}{ Gene } & \multirow[b]{2}{*}{ Polymorphism } & \multicolumn{3}{|l|}{$P$-value } \\
\hline & & Dose normalized Cmax & $\mathrm{T} 1 / 2$ & Tmax \\
\hline \multirow[t]{4}{*}{$A B C B 1$} & $3435 \mathrm{C}>\mathrm{T}$ & 0.474 & 0.069 & 0.274 \\
\hline & $1236 \mathrm{C}>\mathrm{T}$ & 0.220 & 0.586 & 0.597 \\
\hline & $2677 \mathrm{G}>\mathrm{A} / \mathrm{T}$ & 0.220 & 0.586 & 0.597 \\
\hline & $-129 \mathrm{~T}>\mathrm{C}$ & 0.140 & 0.236 & 0.350 \\
\hline \multirow[t]{4}{*}{$A B C C 1$} & ${ }^{\#}(\mathrm{rs} 129081)$ & 0.962 & 0.393 & 0.618 \\
\hline & $825 \mathrm{~T}>\mathrm{C}$ & 0.152 & 0.465 & 0.582 \\
\hline & $1062 \mathrm{~T}>\mathrm{C}$ & 0.180 & 0.661 & 0.705 \\
\hline & $2012 \mathrm{G}>\mathrm{T}$ & 0.313 & 0.891 & 0.721 \\
\hline \multirow[t]{2}{*}{$A B C G 2$} & $346 \mathrm{G}>\mathrm{A}$ & 0.253 & 0.705 & 0.627 \\
\hline & $421 \mathrm{C}>\mathrm{A}$ & 0.498 & 0.399 & 0.280 \\
\hline
\end{tabular}

\#=*801 number from termination codon TGA (5397). 3UTR

Telatinib toxicity was generally mild, with any grade $1-4$ toxicity during all treatment cycles occurring in 23 out of 33 patients $(70 \%)$. Grade 3-4 toxicity was only observed in 3 patients. Hypertension was the most frequently observed side-effect $(n=7)$ and was unrelated to dose [9].

The success rates for all genotyping assays were $100 \%$. Genotype frequencies for 13 of 15 SNPs were in HardyWeinberg equilibrium $(P>0.05) . A B C B 1-129 \mathrm{~T}>\mathrm{C}$ and $A B C C 1$ 2012G $>$ T did not adhere Hardy-Weinberg equilibrium, which was most likely caused by the limited population size. Genotype frequencies for both SNPs were in line with previous publications and frequencies reported in the NCBI database (www.ncbi.nlm.nih.gov).

There was no association between telatinib dose normalized $\mathrm{AUC}_{(0-12)}$ and genetic polymorphisms in $A B C B 1$,
$A B C C 1$, or $A B C G 2$ (Tables 2 and 3). Haploblock for $A B C B 1$ included $3435 \mathrm{C}>\mathrm{T}, 1236 \mathrm{C}>\mathrm{T}$, and $2677 \mathrm{G}>\mathrm{A} / \mathrm{T}$; haploblock for $A B C C 1$ included $825 \mathrm{~T}>\mathrm{C}$, and $1062 \mathrm{~T}>\mathrm{C}$. Haplotype frequencies for $A B C B 1$ were TTT 0.392 , CTT 0.017, TCG 0.093, and CCG 0.498, and for $A B C C 1$ CC 0.197, TC 0.061, and TT 0.724. Also $A B C B 1$ and $A B C C 1$ haplotypes did not show an association with telatinib dose normalized $\mathrm{AUC}_{(0-12)}$. There was also no association between genetic polymorphisms in $A B C B 1, A B C C 1$, or $A B C G 2$ and other investigated $\mathrm{PK}$ parameters, i.e. dose normalized $\mathrm{C}_{\max }, \mathrm{T}_{\max }$ and $\mathrm{T}_{1 / 2}$ (Tables 2 and 3 ).

The number of telatinib treatment courses was not related to any of the genetic polymorphisms and haplotypes analyzed. Since this was an exploratory study with a relatively small number of patients, different dose levels,
Table 4 Association between genetic polymorphisms and telatinib-induced toxicity

\begin{tabular}{|c|c|c|c|c|c|}
\hline \multirow[b]{2}{*}{ Gene } & \multirow[b]{2}{*}{ Polymorphism } & \multirow[b]{2}{*}{ Genotype } & \multicolumn{2}{|c|}{ Toxicity: any toxicity grade $1-4$ all cycles } & \multirow[b]{2}{*}{$P$-value } \\
\hline & & & No & Yes & \\
\hline \multirow[t]{5}{*}{ FLT4 } & \multirow[t]{2}{*}{$1480 \mathrm{~A}>\mathrm{G}$} & AA & 7 & 20 & \multirow[t]{2}{*}{0.336} \\
\hline & & $\mathrm{AG}$ & 3 & 3 & \\
\hline & \multirow[t]{3}{*}{$2670 \mathrm{C}>\mathrm{G}$} & $\mathrm{CC}$ & 6 & 11 & \multirow[t]{3}{*}{0.813} \\
\hline & & CG & 3 & 9 & \\
\hline & & GG & 1 & 3 & \\
\hline \multirow[t]{9}{*}{$K D R$} & \multirow[t]{3}{*}{$1719 \mathrm{~A}>\mathrm{T}$} & $\mathrm{AA}$ & 1 & 1 & \multirow[t]{3}{*}{0.809} \\
\hline & & TA & 4 & 9 & \\
\hline & & TT & 5 & 13 & \\
\hline & \multirow[t]{3}{*}{$-604 \mathrm{~T}>\mathrm{C}$} & $\mathrm{CC}$ & 3 & 7 & \multirow[t]{3}{*}{0.870} \\
\hline & & $\mathrm{CT}$ & 5 & 13 & \\
\hline & & $\mathrm{TT}$ & 2 & 3 & \\
\hline & \multirow[t]{3}{*}{$1192 \mathrm{G}>\mathrm{A}$} & $\mathrm{CC}$ & 5 & 19 & \multirow[t]{3}{*}{0.091} \\
\hline & & $\mathrm{TC}$ & 4 & 4 & \\
\hline & & $\mathrm{TT}$ & 1 & 0 & \\
\hline
\end{tabular}


different tumor types, and variable previous treatment lines association analyses between polymorphisms and treatment outcome were not performed.

No association between any grade $1-4$ toxicity and $K D R$ or FLT4 genotype or haplotype was observed (Table 4).

\section{Discussion}

The development of tailor-made pharmaceutics is especially useful in the field of oncology, as most standard anticancer agents have a very narrow therapeutic index, leading to nonspecific anti-tumor response in combination with a high level of side effects. For example, in 3-5\% of patients with severe 5-FU-related toxicity. dihydropyrimidine dehydrogenase (DPD) deficiencies are described $[10,11]$. In addition, the genetic variant of the gene encoding UDP glucuronosyltransferase (UGT) 1A1 polymorphism, UGT1A1*28, is associated with a higher incidence of toxicity, mostly hematological toxicity, in irinotecan treatment [12-14].

Most research to improve cancer treatment through genetics has focused on polymorphisms in genes encoding the drug transporters and drug metabolizing enzymes but less is known about genetic variation in drug targets. Directing treatment on the vascular endothelial growth factor (VEGF) pathway, one of the key players in angiogenesis, is a focus of more recent research. VEGF inhibitors have only become available for clinical use in the last few years and consequently, very little is known regarding the influence of polymorphisms in VEGF or its receptor, VEGFR $[15,16]$. One CA repeat polymorphism in the KDR (VEGFR2)) gene is described previously, with a higher promoter activity in the 11-repeat polymorphism compared to the 12-repeat polymorphism [17]. Four SNPs in the $K D R$ gene were identified by Park et al $(-92 \mathrm{G}>\mathrm{A}$, $54 \mathrm{~A}>\mathrm{G}, 889 \mathrm{G}>\mathrm{A}$, and $1416 \mathrm{~T}>\mathrm{A}$ ) and associated with atopy [18]. Recently, Schneider et al reported that $K D R$ genotypes were not associated with toxicity or efficacy of paclitaxel with or without bevacizumab treatment in advanced breast cancer patients [19].

VEGF inhibitors can induce very specific side effects which are hard to predict. This is even more relevant while in future use these angiogenesis inhibitors most likely will be combined with various chemotherapeutic agents. Pharmacogenetic research might help to identify the patients at risk for specific side effects and select patients or doses needed for optimal treatment without adding potentially harmful side effects.

In this exploratory study we could not find an association between polymorphisms in genes encoding transporter proteins and telatinib pharmacokinetics or between drug target gene polymorphisms and telatinib induced toxicity. This lack of association might be explained by, for example, the limited number of patients, the relatively limited toxicity, and the variability in tumor types, number of previous treatment lines, and performance scores. Since toxicity was limited we used toxicity reported over all treatment cycles. This may have caused bias, and therefore number of treatment cycles was used as a covariate in the multivariate analysis. Since different telatinib doses were used, we corrected by associating polymorphisms with dose normalized $\mathrm{AUC}_{(0-12)}$.

Pharmacogenetic testing is important for all new drug applications. Knowledge on pharmacokinetics and pharmacodynamics of both registered and new developing drugs is increasing far more rapidly than the knowledge on genetic variants in metabolizing enzymes, transporters and drug target genes [1, 20, 21]. Therefore, DNA collection for future genetic studies, retrospective and prospective, is required and all patients in clinical trials should be asked to consent for DNA collection for future studies. Often side effects are based on single gene polymorphisms affecting drug metabolism, interaction with cellular targets or transport. Therefore, hypothesis based pharmacogenetic research of candidate genes is important in phase I and II studies to limit the number of patients unnecessarily exposed to a toxic dose or drug. This information may reduce the size, costs and duration of subsequent phase III studies.

In general, in the preclinical and phase I setting little is known about drug pharmacokinetics and pharmacodynamics. With this exploratory study we tried to increase that knowledge, because, despite of the rapidly increasing use of VEGF inhibitors, the knowledge of determinants that predict response and toxicity in the individual patient is still lacking. Therefore, it remains highly important to conduct pharmacogenetic association studies in early drug development in order to increase knowledge on interpatient variability of drug response.

Acknowledgements of research support Research was funded by Bayer s.a.-n.v. Brussels, Belgium/Bayer AG Leverkusen, Germany.

Open Access This article is distributed under the terms of the Creative Commons Attribution Noncommercial License which permits any noncommercial use, distribution, and reproduction in any medium, provided the original author(s) and source are credited.

\section{References}

1. Auman JT, McLeod HL (2008) Cancer pharmacogenomics: DNA genotyping and gene expression profiling to identify molecular determinants of chemosensitivity. Drug Metab Rev 40:303-315

2. Swen JJ, Huizinga TW, Gelderblom H, de Vries EG, Assendelft WJ, Kirchheiner J, Guchelaar HJ (2007) Translating pharmacogenomics: challenges on the road to the clinic. PLoS Med 4:e209

3. Investigator's brochure BAY 57-9352 (Telatinib) (2007) Bayer Healthcare. Martville, NJ, USA 
4. Eskens FA, Steeghs N, Verweij J, Bloem JL, Christensen O, van Doorn L, Ouwerkerk J, de Jonge MJ, Nortier JW, Kraetzschmar J, Rajagopalan P, Gelderblom H (2009) Phase I dose escalation study of telatinib, a tyrosine kinase inhibitor of vascular endothelial growth factor receptor 2 and 3, platelet-derived growth factor receptor beta, and c-Kit, in patients with advanced or metastatic solid tumors. J Clin Oncol 27:4169-4176

5. Strumberg D, Clark JW, Awada A, Moore MJ, Richly H, Hendlisz A, Hirte HW, Eder JP, Lenz HJ, Schwartz B (2007) Safety, pharmacokinetics, and preliminary antitumor activity of sorafenib: a review of four phase I trials in patients with advanced refractory solid tumors. Oncologist 12:426-437

6. Faivre S, Delbaldo C, Vera K, Robert C, Lozahic S, Lassau N, Bello C, Deprimo S, Brega N, Massimini G, Armand JP, Scigalla P, Raymond E (2006) Safety, pharmacokinetic, and antitumor activity of SU11248, a novel oral multitarget tyrosine kinase inhibitor, in patients with cancer. J Clin Oncol 24:2535

7. Therasse P, Arbuck SG, Eisenhauer EA, Wanders J, Kaplan RS, Rubinstein L, Verweij J, Van GM, van Oosterom AT, Christian MC, Gwyther SG (2000) New guidelines to evaluate the response to treatment in solid tumors. European Organization for Research and Treatment of Cancer, National Cancer Institute of the United States, National Cancer Institute of Canada. J Natl Cancer Inst 92:205-216

8. Purcell S, Neale B, Todd-Brown K, Thomas L, Ferreira MA, Bender D, Maller J, Sklar P, de Bakker PI, Daly MJ, Sham PC (2007) PLINK: a tool set for whole-genome association and population-based linkage analyses. Am J Hum Genet 81:559575

9. Steeghs N, Gelderblom H, Roodt JO, Christensen O, Rajagopalan P, Hovens M, Putter H, Rabelink TJ, de Koning E (2008) Hypertension and rarefaction during treatment with telatinib, a small molecule angiogenesis inhibitor. Clin Cancer Res 14:3470-3476

10. Diasio RB (2001) Clinical implications of dihydropyrimidine dehydrogenase on 5-FU pharmacology. Oncology (Williston Park) $15: 21-26$

11. Ridge SA, Sludden J, Wei X, Sapone A, Brown O, Hardy S, Canney P, Fernandez-Salguero P, Gonzalez FJ, Cassidy J, McLeod HL (1998) Dihydropyrimidine dehydrogenase pharmacogenetics in patients with colorectal cancer. Br J Cancer 77:497-500
12. Iyer L, Das S, Janisch L, Wen M, Ramirez J, Karrison T, Fleming GF, Vokes EE, Schilsky RL, Ratain MJ (2002) UGT1A1*28 polymorphism as a determinant of irinotecan disposition and toxicity. Pharmacogenomics J 2:43-47

13. Innocenti F, Undevia SD, Ramirez J, Mani S, Schilsky RL, Vogelzang NJ, Prado M, Ratain MJ (2004) A phase I trial of pharmacologic modulation of irinotecan with cyclosporine and phenobarbital. Clin Pharmacol Ther 76:490-502

14. Kweekel DM, Gelderblom H, der ST Van, Antonini NF, Punt CJ, Guchelaar HJ (2008) UGT1A1*28 genotype and irinotecan dosage in patients with metastatic colorectal cancer: a Dutch Colorectal Cancer Group study. Br J Cancer 99:275-282

15. Pander J, Gelderblom H, Guchelaar HJ (2007) Pharmacogenetics of EGFR and VEGF inhibition. Drug Discov Today 12:1054-1060

16. Pasqualetti G, Danesi R, Del TM, Bocci G (2007) Vascular endothelial growth factor pharmacogenetics: a new perspective for anti-angiogenic therapy. Pharmacogenomics 8:49-66

17. Kariyazono H, Ohno T, Khajoee V, Ihara K, Kusuhara K, Kinukawa N, Mizuno Y, Hara T (2004) Association of vascular endothelial growth factor (VEGF) and VEGF receptor gene polymorphisms with coronary artery lesions of Kawasaki disease. Pediatr Res 56:953-959

18. Park HW, Lee JE, Shin ES, Lee JY, Bahn JW, Oh HB, Oh SY, Cho SH, Moon HB, Min KU, Elias JA, Kim YY, Kim YK (2006) Association between genetic variations of vascular endothelial growth factor receptor 2 and atopy in the Korean population. J Allergy Clin Immunol 117:774-779

19. Schneider BP, Wang M, Radovich M, Sledge GW, Badve S, Thor A, Flockhart DA, Hancock B, Davidson N, Gralow J, Dickler M, Perez EA, Cobleigh M, Shenkier T, Edgerton S, Miller KD (2008) Association of vascular endothelial growth factor and vascular endothelial growth factor receptor-2 genetic polymorphisms with outcome in a trial of paclitaxel compared with paclitaxel plus bevacizumab in advanced breast cancer: ECOG 2100. J Clin Oncol 26:4672-4678

20. Relling MV, Hoffman JM (2007) Should pharmacogenomic studies be required for new drug approval? Clin Pharmacol Ther $81: 425-428$

21. Roses AD (2008) Pharmacogenetics in drug discovery and development: a translational perspective. Nat Rev Drug Discov $7: 807-817$ 